\title{
RESEARCH
}

\section{Erythropoietin-receptor agonists in critically ill patients: a meta-analysis of randomized controlled trials}

\author{
Ryan Zarychanski MD, Alexis F. Turgeon MD MSc, Lauralyn Mclntyre MD MHSc, \\ Dean A. Fergusson MHA PhD
}

$\infty \quad$ See related article page 747

\section{ABSTRACT}

Introduction: Anemia and the need for red blood cell transfusions are common among patients admitted to intensive care units. Erythropoietin has been used to decrease the need for transfusions; however, its ability to improve clinical outcomes is unknown. We evaluated the effect of erythropoietinreceptor agonists on clinically important outcomes, including mortality, length of stay in hospital or intensive care unit, ventilator use, transfusion requirements and major adverse events.

Methods: To identify relevant studies, we searched electronic databases covering 1950 to 2007 (MEDLINE, EMBASE, the Cochrane Central Register of Controlled Trials and the Scopus database). We also searched conference proceedings and grey literature sources. We selected all randomized controlled trials involving critically ill patients that compared an erythropoietin-receptor agonist with a placebo or no intervention. No language restrictions were considered. Data were extracted using a standardized extraction template. We used a fixed effects model to calculate all summary measures of treatment effects.

Results: Of 673 identified records, 9 studies that investigated erythropoietin alpha met the eligibility criteria and were included in our analysis. Erythropoietin, compared with placebo or no intervention, had no statistically significant effect on overall mortality (odds ratio [OR] $0.86,95 \%$ confidence interval $[\mathrm{Cl}] 0.71-1.05, \mathrm{I}^{2}=0 \%$ ). The treatment and control groups did not differ in the length of stay in hospital or intensive care unit, or in the duration of mechanical ventilation, in the 3 studies that reported these outcomes. Erythropoietin, compared with placebo, significantly reduced the odds of a patient receiving at least 1 transfusion (OR $0.73,95 \% \mathrm{Cl} 0.64-0.84, \mathrm{I}^{2}=54.7 \%$ ). The mean number of units of blood transfused per patient was decreased by 0.41 units in the erythropoietin group $(95 \% \mathrm{Cl} 0.10-0.74$, $\mathrm{I}^{2}=79.2 \%$ ). Most of the included studies were performed before the widespread adoption of a restrictive transfusion strategy. Only 1 study provided detailed reports of adverse events, and none of the studies systematically evaluated all patients for venous thromboembolism.

Interpretation: At this time, we do not recommend the routine use of erythropoietin-receptor agonists in critically ill patients. The reduction in red blood cell transfusions per patient was very small, and there is insufficient evidence to determine whether this intervention results in clinically important benefits with acceptable risks.

Une version française de ce résumé est disponible à l'adresse www.cmaj.ca/cgi/content/full/177/7/725/DCI

\section{CMAJ 2007;177(7):725-34}

Published at www.cmaj.ca on Sept. 5, 2007.

A nemia and the need for allogeneic blood transfusion are common among patients who are critically ill. Observational studies have shown that anemia develops in $95 \%$ of patients admitted to intensive care units for 3 or more days. ${ }^{1-3}$ Studies in western Europe and North America have demonstrated that $42 \%-50 \%$ of patients admitted to intensive care units will require transfusion of packed red blood cells because of anemia. ${ }^{2,4}$ About $85 \%$ of patients admitted to an intensive care unit for more than $\mathrm{I} 3$ days will require such transfusions. ${ }^{2}$

Anemia can occur in critically ill patients for a variety of reasons, such as blood loss related to a surgical procedure, trauma and gastrointestinal bleeding. A less conspicuous, but equally important, cause of anemia is repetitive phlebotomy for surveillance and diagnosis. On average, 4I $\mathrm{mL}$ of blood is taken for laboratory testing per day of stay in an intensive care unit; ${ }^{4,5}$ however, this amount can exceed $240 \mathrm{~mL}$ per day in some surgical units. ${ }^{6}$ Anemia of inflammation, also known as anemia of chronic disease, is another important subtype of anemia in this patient population. About two-thirds of critically ill patients receive allogeneic blood because their hemoglobin level falls below a threshold value. ${ }^{7}$

Blood transfusions are known to have rare but serious adverse consequences, including transfusion-associated circulatory overload, transfusion-transmitted infections and transfusion-associated acute lung injury. Given the fre-

From the Department of Epidemiology and Community Medicine (Zarychanski, Mclnytre, Fergusson), University of Ottawa; the Ottawa Health Research Institute (Zarychanski, Mclntyre, Fergusson), The Ottawa Hospital, Ottawa, Ont.; and the Centre Hospitalier Affilié Universitaire de Québec Research Center, the Department of Anesthesia and the Division of Critical Care Medicine (Turgeon), Laval University, Québec City, Que. 
quent need for red blood cell transfusions in intensive care units and the risks associated with the administration of blood products, experimental studies of recombinant erythropoietin have been conducted. ${ }^{1,8-15}$ In an effort to overcome the relative erythropoietin deficiency observed in critically ill patients, recombinant erythropoietin has been used to stimulate erythropoiesis, mitigate anemia and reduce the need for blood transfusions. Early proof-ofconcept studies were generally small and focused on hematologic response as an outcome measure. Larger trials have subsequently been conducted that permit the examination of clinical outcomes and safety.

The utility of erythropoietin-receptor agonists in the setting of critical illness is unclear despite the publication of several randomized controlled trials. We performed this systematic review to investigate the clinical benefits and harms associated with the use of erythropoietin-receptor agonists in critically ill patients.

\section{Methods}

We performed our meta-analysis using methods and analytic strategies designed and approved by 2 of us (A.F.T. and D.A.F.) This protocol is available online (Appendix I, www.cmaj.ca /cgi/content/full//77/7/725/DC2).

\section{Search}

We developed a strategy to search OVID MEDLINE (1950-2007 February week I). This search strategy was adapted to search EMBASE (1980-2007 February week I) and the Cochrane Central Register of Controlled Trials (to first quarter 2007). The search strategy was developed with the help of an information specialist at The Ottawa Hospital. It underwent several iterations and was updated I month before publication. The complete MEDLINE search strategy is presented in Appendix 2 (available online at www.cmaj.ca/cgi /content/full//777/7/725/DC2). To identify ongoing or planned trials of erythropoietin-receptor agonists, we also searched the ClinicalTrial.gov database. We used the SIGLE (System for Information on Grey Literature) database and Google Scholar to assist in the identification of relevant grey literature. We contacted representatives from the manufacturers of erythropoietin-receptor agonists (Amgen, Ortho-Biotech, Roche), corresponding or first authors of all included trials and subject-area experts for information about ongoing studies. We searched the abstracts and conference proceedings from the Society of Critical Care Medicine, the European Society of Intensive Care Medicine and the International Symposium on Intensive Care Medicine (2002-2007 February). In addition, we canvassed the Scopus abstract and citation database, and we examined the individual bibliographies of all included trials and relevant reviews to minimize the omission of potentially relevant trials. No language restrictions were applied.

\section{Selection}

We included studies that met the following criteria: the treatment groups were randomly assigned; erythropoietin or darbepoietin was compared with a placebo, alternative ther- apy or no intervention; patients were admitted to an intensive care unit; enrolled patients were I year of age or older. Studies were excluded if there was exclusive enrolment of cardiac surgery patients or if erythropoietin-receptor agonists were administered preoperatively to decrease the need for perioperative transfusions.

Our primary outcome measure was death, regardless of the primary outcome of the included studies. Our secondary outcomes were length of stay in an intensive care unit or hospital, duration of mechanical ventilation and adverse events due to erythropoietin-receptor agonists (e.g., arterial and venous thrombosis, hypertension). Our secondary outcome measures also included transfusion-related outcomes, including transfusion independence (i.e., the ability of erythropoietin-receptor agonists to prevent the need for transfusion), units of blood transfused per patient and adverse events related to transfusion.

\section{Quality assessment}

The title, abstract and keywords of each identified record were screened for relevancy (level I screen) by 2 of us (R.Z. and A.F.T.) as the primary reviewers. Nonrelevant records agreed upon for exclusion by both reviewers were eliminated at this stage. Full-text articles were obtained for all remaining records. Non-English abstracts were translated as required. The same 2 reviewers independently assessed each full-text article, applying the inclusion and exclusion criteria (level 2 screen) to determine the studies to be included. Interrater agreement was calculated at each screening level with the use of Cohen's kappa statistic. Discrepancies were resolved by means of consensus, and with input from the senior author (D.A.F.) if necessary.

The 2 primary reviewers independently assessed the methodologic quality of each of the included studies using the scale previously validated by Jadad and colleagues. ${ }^{16} \mathrm{We}$ assessed allocation concealment using the method developed by Schultz and colleagues. ${ }^{17}$ The Jadad scale gives a score for methodologic quality based on the reported methods and description of randomization (o-2 points), blinding (o-2 points) and participant withdrawals (I point). Possible scores varied from o to 5 , with 5 representing the highest methodologic quality. Information about methodologic quality and potential risks of bias were used to guide sensitivity analyses and to explore sources of heterogeneity.

\section{Data abstraction}

The 2 primary reviewers extracted data from the included studies independently and without blinding using a standardized data extraction form. The form was initially piloted to ensure completeness and usability. If required data were ambiguous or missing, we contacted the authors of the study for clarification or additional data.

\section{Data synthesis}

We analyzed discrete and continuous data using the Cochrane Review Manager (version 4.2.10). We used an electronic double-data entry system to minimize transcription errors. We employed a fixed-effects model using inverse vari- 
ance weights for all summary measures of effect. Intentionto-treat analysis was performed using available cases. For dichotomous data, we expressed summary measures of effect across studies as odds ratios with $95 \%$ confidence intervals. An odds ratio of less than I suggests a lower rate of the outcome (e.g., death) among patients given an erythropoietinreceptor agonist than among those in the control group. Measures of effect for continuous data (units of packed red blood cells per patient) were expressed as weighted mean differences with $95 \%$ confidence intervals.

We assessed evidence of statistical heterogeneity using the $\mathrm{I}^{2}$ statistic. This statistic can be interpreted as the proportion of total variation across studies that is due to heterogeneity (min-max, $0 \%-100 \%) .{ }^{18}$ We investigated potential sources of heterogeneity by conducting a sensitivity analyses based on study characteristics, including dosing regimen (high v. standard dose). The data did not permit analyses based on the total dose of drug delivered. We explored evolving transfusion practices by considering the influence of liberal (hemoglobin $\geq 90 \mathrm{~g} / \mathrm{L}$ ) versus restrictive (hemoglobin $\leq 80 \mathrm{~g} / \mathrm{L}$ ) transfusion practices. Sensitivity analyses based on methodologic quality were also conducted. We visually explored the potential for publication bias for each outcome using funnel plots.

\section{Results}

\section{Search results}

Of the 673 records identified, 618 were excluded after level I

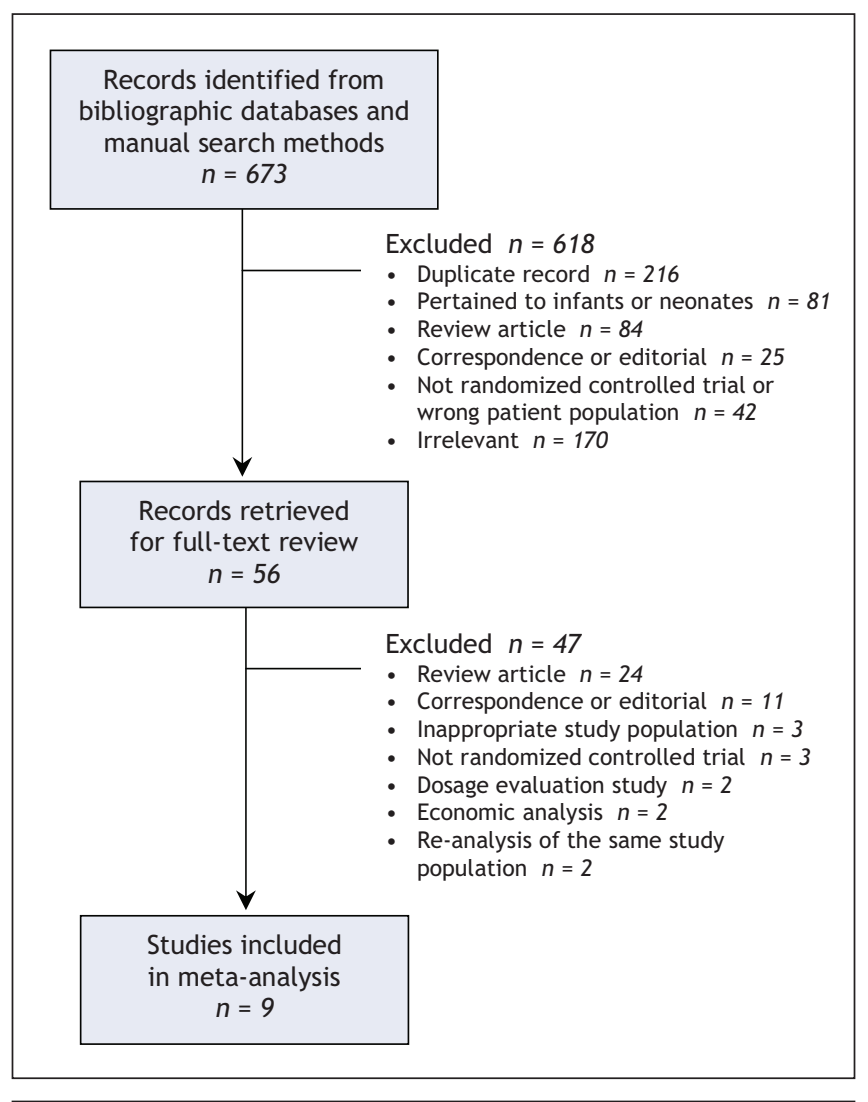

Figure 1: Selection of studies for meta-analysis. screening: 2I6 were duplicate records, 402 were excluded for other reasons (Figure I). The agreement between the 2 primary reviewers at this level of screening was substantial (estimated kappa $=0.77) .{ }^{19}$ The full-text articles for 56 studies were retrieved, and after level 2 screening, Io articles were selected for inclusion in the meta-analsysis. Agreement between the 2 reviewers at the second level of screening was almost perfect (estimated kappa $=0.94$ ), and the single discrepancy was resolved by consensus. ${ }^{19}$ The reasons for excluding studies at both level I and 2 screening are listed in Figure I. We did not identify any records from grey literature sources. During the process of data extraction, it became apparent that 2 publications were separate analyses of the same study; ${ }^{15,20}$ thus, we included the article that was most informative for the purpose of this review. ${ }^{15}$

\section{Study characteristics}

A total of 3326 participants were enrolled in the 9 included studies. All of the studies were published in peer-reviewed, English-language journals and were sponsored by the same parent company. ${ }^{1,8-15}$ Five of the studies were conducted in North America, $, 18,9,12,13$ and 4 were conducted in Europe. ${ }^{10,11,14,15}$ Of the 9 studies, 4 enrolled more than roo patients. ${ }^{1,8,9,11}$ All 9 studies appeared to enrol only adults, but the explicit age criteria were not stated in 2 of the articles. ${ }^{10,13}$ Seven studies included patients admitted to mixed medical and surgical intensive care units, ${ }^{1,8-11,14,15}$ I included patients admitted to a long-term acute care facility, ${ }^{12}$ and I included patients admitted to a burn unit (Table I). ${ }^{13}$

All of the trials compared erythropoietin alpha with either a placebo ${ }^{1,8-10,12,13,15}$ or no therapy. ${ }^{11,14}$ No eligible studies of darbepoietin were identified. In 8 of the included studies, all of the participants received iron supplementation as a cointervention. In the remaining study, iron was administered to $42 \%$ of patients who received erythropoietin and $24 \%$ of patients in the control group. ${ }^{13}$ Iron was administered either enterally or intravenously depending on the patient's gut function and the study protocol.

The mean hemoglobin concentration before transfusion was between 75 (standard deviation [SD] 9) g/L and 93 (SD I3) $\mathrm{g} / \mathrm{L}$ (Table I). A liberal transfusion strategy (target hemoglobin $\geq 90 \mathrm{~g} / \mathrm{L}$ ) was used in 4 studies, ${ }^{1,10,13,14}$ and a restrictive transfusion strategy (hemoglobin $\leq 80 \mathrm{~g} / \mathrm{L}$ ) was practised in 3 studies. ${ }^{9,11,12}$ A mandated transfusion protocol was reported in 2 of the trials $\mathrm{s}^{11,14}$ and was inferred from 2 other studies (Table I). ${ }^{10,13}$ The remaining studies either had no stated transfusion criteria ${ }^{1,15}$ or offered practice suggestions that were not mandated within the context of a study protocol. ${ }^{8,9,12}$ The transfusion practice adopted by each study (liberal or restrictive) was inferred from the mean hemoglobin concentration before transfusion.

Erythropoietin dosing varied between the studies, as did the maximum duration of therapy (Table I). In 5 of the 9 studies, a fixed dose of erythropoietin was administered, and in 4 studies dosing was based on patient weight (units $/ \mathrm{kg}$ ). The most frequent ( $89.9 \%$ of patients) dosing regimen was 40000 units per week ${ }^{8,9,12,15}$; however, the dose of erythropoietin per week (based on $70 \mathrm{~kg}$ ) varied from 36750 to 160 ooo units. 


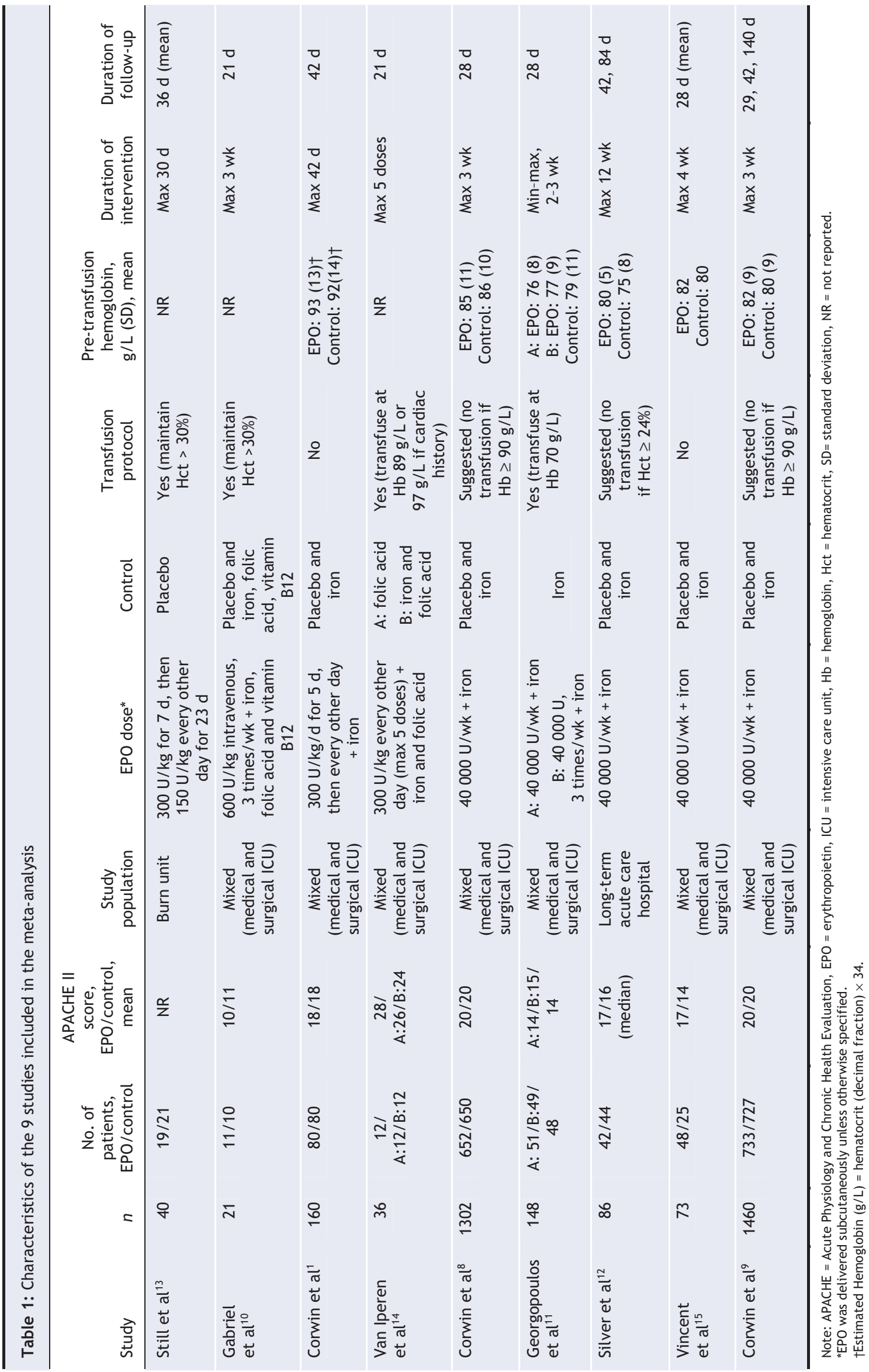


The study by Georgopoulos and colleagues had 2 treatment groups, each with different erythropoietin dosing schedules. ${ }^{11}$ Data for patients in the 2 groups were pooled for the purposes of this meta-analysis. The study by Van Iperen and colleagues included 2 control groups,${ }^{14}$ and for the purpose of our metaanalysis, we considered the group that received iron as the comparator group.

The maximum duration of the intervention period (period when erythropoietin or placebo was administered) varied from 3 to 12 weeks. The length of follow-up varied from 2I to I40 days, and the length of follow-up was not always the same as the length of the intervention period (Table I). The follow-up periods that were used to determine the summary effect measures of mortality and the transfusion differences were between 2I and 42 days. Reporting of adverse events and the related analyses were adjudicated at the study closeout, which varied from 2I to I4O days.

The primary outcomes in 6 of the included studies were transfusion related (decreased amount of blood transfused or facilitation of transfusion independence).$^{1,8,9,11-13}$ In 4 studies, laboratory results were included as primary end points, ${ }^{10,11,14,15}$ including reticulocyte counts or levels of circulating early peripheral blood erythroid progenitors, hemoglobin and hematocrit levels, indices of cytokine production, serum erythropoietin concentration and serum iron indices. Several studies reported or inferred both transfusion-related end points and laboratory results as primary outcomes. None of the studies included death, length of stay, measures of organ dysfunction or quality of life as primary outcomes.

\section{Assessment of methodologic quality}

Of the 9 included studies, 3 were of high methodologic quality (Table 2). ${ }^{8,9,12}$ Adequate allocation concealment was reported in 3 of the studies.$^{8,9,11}$ Two studies were not blinded, ${ }^{11,14}$ and I did not use intention-to-treat analysis of all randomized patients when performing statistical analyses. ${ }^{10}$
Six of the studies reported losses to follow-up that varied from $5.1 \%^{8}$ to $27 \%^{12}$ (Table 2 ).

\section{Data synthesis}

\section{Death}

We pooled the data from the 9 included studies $(n=3314)$ to generate a summary odds ratio (OR) for mortality (Figure 2). We found that the use of erythropoietin, compared with placebo or no intervention, was not associated with a statistically significant reduction in the overall rate of death from all causes (OR $0.86,95 \% \mathrm{CI} 0.7 \mathrm{I}-\mathrm{I} .05, \mathrm{I}^{2}=0 \%$ ). No statistical evidence of heterogeneity was detected.

We performed sensitivity analyses to evaluate mortality among the different patient subgroups (Figure 3). Among patients admitted to mixed medical and surgical units (the 2 trials that enrolled patients with burns ${ }^{13}$ or patients admitted to a long-term acute care hospital ${ }^{12}$ were excluded), the reduction in death remained nonsignificant (OR 0.88 , 95\% $\mathrm{CI} 0.72-\mathrm{I} .07, \mathrm{I}^{2}=0 \%$ ). Among patients who received 40000 units of erythropoietin per week, the OR for death was 0.82 (95\% CI o.66-I.02, $\mathrm{I}^{2}=0 \%$ ). ${ }^{18,19,11,12,15}$ Among patients who received more than 40000 units weekly, there was a trend toward harm (OR I.26, 95\% CI 0.74-2.I5, $\mathrm{I}^{2}=0 \%$ ). ${ }^{1,10,11,14}$ The pooled OR for death was of borderline significance among studies that used a restrictive (hemoglobin $\leq 80 \mathrm{~g} / \mathrm{L}$ ) transfusion practice that was either mandated or in keeping with current practice patterns (OR $0.73,95 \%$ CI $0.53-$ I.00, $\left.\mathrm{I}^{2}=0 \%\right),{ }^{9,11,12}$ but it was nonsignificant among studies that adopted a liberal (hemoglobin $\geq 90 \mathrm{~g} / \mathrm{L}$ ) transfusion practice (OR I.I8, 95\% CI 0.66-2.II, $\mathrm{I}^{2}=0 \%$ )..$^{1,10,13,14}$ A nonsignificant reduction in death was observed among the studies of high methodologic quality (OR 0.8I, 95\% CI 0.65-I.0I, $\left.\mathrm{I}^{2}=2.8 \%\right) .{ }^{8,9,12}$ No significant reduction in mortality was observed among the unblinded studies (OR $\mathrm{r} .03,95 \% \mathrm{CI}$ $\left.0.42-2.53, \mathrm{I}^{2}=0 \%\right){ }^{11,14}$ In the 3 studies that reported ade-

Table 2: Methodologic quality and potential risks of bias of the 9 randomized controlled trials (RCTs) included in the systematic review

\begin{tabular}{|c|c|c|c|c|c|c|c|c|}
\hline \multirow[b]{2}{*}{ Study } & \multirow[b]{2}{*}{ RCT type } & \multirow[b]{2}{*}{ Sponsor } & \multicolumn{4}{|c|}{ Jadad score* } & \multirow[b]{2}{*}{$\begin{array}{c}\text { Allocation } \\
\text { concealment }\end{array}$} & \multirow[b]{2}{*}{$\begin{array}{l}\text { Intention-to- } \\
\text { treat analysis }\end{array}$} \\
\hline & & & Total & Randomization & Blinding & $\begin{array}{c}\text { Attrition } \\
\text { information }\end{array}$ & & \\
\hline Still et $\mathrm{al}^{13}$ & Multicentre & $\begin{array}{l}\text { Johnson and } \\
\text { Johnson }\end{array}$ & 2 & 1 & 1 & 0 & Unclear & Yes \\
\hline Gabriel et $\mathrm{al}^{10}$ & Single centre & Janssen-Cilag & 3 & 1 & 2 & 1 & Unclear & No \\
\hline Corwin et $\mathrm{al}^{1}$ & Multicentre & Ortho-Biotech & 3 & 2 & 1 & 0 & Unclear & Yes \\
\hline $\begin{array}{l}\text { Van Iperen } \\
\text { et } \mathrm{al}^{14}\end{array}$ & Single centre & Janssen-Cilag & 2 & 1 & 0 & 1 & Unclear & Yes \\
\hline Corwin et $\mathrm{al}^{8}$ & Multicentre & Ortho-Biotech & 5 & 2 & 2 & 1 & Adequate & Yes \\
\hline $\begin{array}{l}\text { Georgopoulos } \\
\text { et } \mathrm{al}^{11}\end{array}$ & Multicentre & Janssen-Cilag & 1 & 1 & 0 & 0 & Adequate & Yes \\
\hline Silver et $\mathrm{al}^{12}$ & Multicentre & Ortho-Biotech & 5 & 2 & 2 & 1 & Unclear & Yes \\
\hline Vincent et $\mathrm{al}^{15}$ & Multicentre & Janssen-Cilag & 4 & 1 & 2 & 1 & Unclear & Yes \\
\hline Corwin et $\mathrm{al}^{9}$ & Multicentre & Ortho-Biotech & 5 & 2 & 2 & 1 & Adequate & Yes \\
\hline
\end{tabular}

*The Jadad scale ${ }^{16}$ gives a score for methodologic quality based on the reported methods and description of randomization (0-2 points), blinding (0-2 points) and participant withdrawals (0-1 point). Possible scores vary from 0 to 5 , with a score of 5 indicating high methodologic quality. 


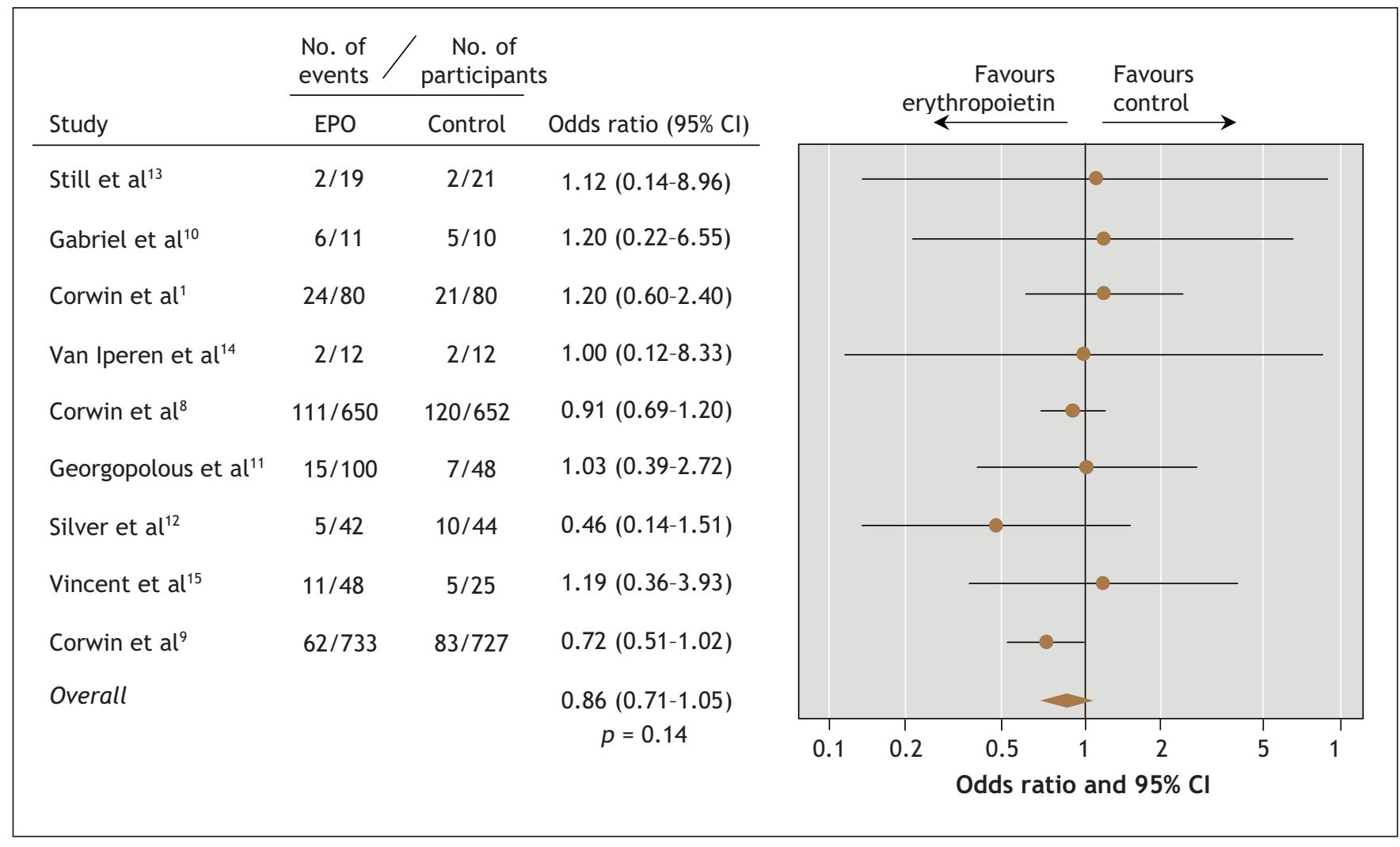

Figure 2: Analysis of mortality in selected trials of erythropoietin use in critially ill patients. Note: $\mathrm{EPO}=$ erythropoietin, $\mathrm{Cl}=\mathrm{confidence}$ interval.

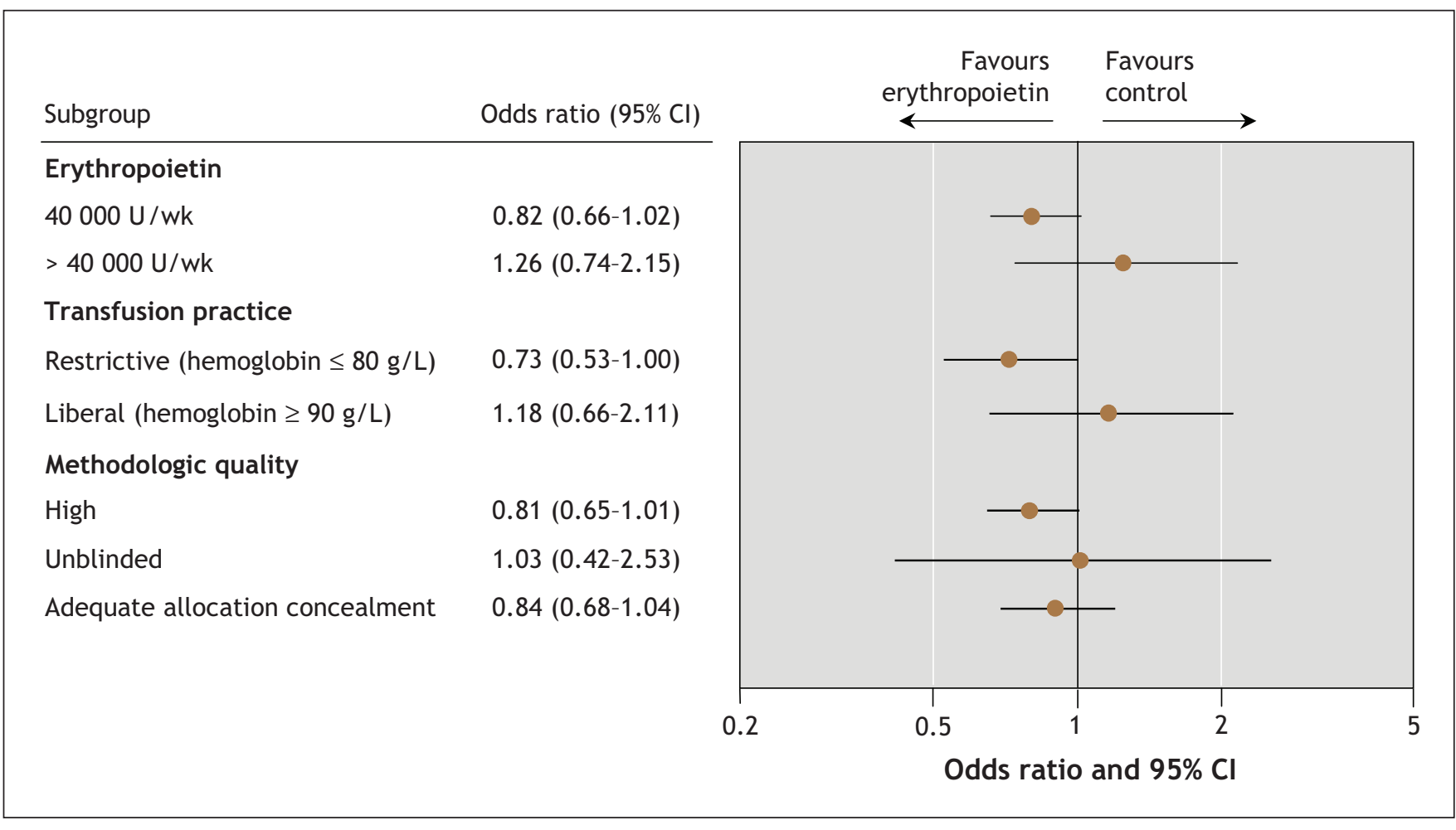

Figure 3: Mortality sensitivity analysis of studies included in the meta-analysis of erythropoietin use in critically ill patients. Note: $\mathrm{Cl}=$ confidence interval. 
quate allocation concealment, the pooled OR for death was 0.84 (95\%CI 0.68-I.04, $\left.\mathrm{I}^{2}=0 \%\right){ }^{8,11}$

\section{Length of stay and ventilator use}

Of the 9 included studies, 3 reported a similar median length of hospital stay for the erythropoietin and control groups (I9 and 2 I days $;{ }^{8}$ I5 and 15 days; $; 68$ and 62 days ${ }^{12}$ ). These studies included $84.0 \%(2794 / 3326)$ of the randomized study population. ${ }^{8,9,12}$ No measures of variation were provided. Outcomes that reflected the length of time spent in an intensive care unit were reported in 4 studies as the median or mean length of stay in an intensive care unit, and I study reported "intensive care unit-free days." ${ }^{-11}$ Regardless of this difference in reporting, the amount of time spent in an intensive care unit was similar in all studies. Four of the studies reported outcomes pertaining to ventilator use..$^{8,9,11,12}$ None of the studies found a statistically significant difference in the duration of mechanical ventilation, the number of ventilator-free days or successful weaning..$^{8,9,11,12}$ Length of stay and ventilator use were not suitable for pooled analyses owing to variation in the reporting methods.

\section{Adverse events}

Six of the studies included information about adverse events (Table 3); however, most adverse events, diagnostic procedures and surveillance mechanisms were not clearly or reproducibly defined. One study reported the acquired incidence of myocardial infarction to be $2.1 \%$ ( $15 / 728)$ among patients who received erythropoietin, compared with $0.8 \%(6 / 720)$ in the control group (OR 2.50, 95\% CI 0.97-6.49). ${ }^{9}$ Only I study reported data on the development of hypertension (Table 3$).^{15}$
Five of the studies reported deep vein thrombosis as an adverse event. ${ }^{1,8,9,11,13}$ No study reported systematic screening methods for venous thrombosis. The pooled OR for the occurrence of deep vein thrombosis associated with erythropoietin use was I.32 (95\% CI 0.95-I.84, $\mathrm{I}^{2}=0 \%$ ).

Given that the presumed benefit of erythropoietin is a reduced need for transfusion, we would expect that there would be parallel reductions in blood use and transfusion-related adverse events, such as transfusion-associated circulatory overload, transfusion-related acute lung injury and bloodstream infections. None of the studies reported transfusion reactions, pulmonary edema or acute lung injury. Bloodstream infections were not reported, but the proportion of patients with an acquired diagnosis of sepsis was reported in 3 studies and was not significantly different between the treatment and control groups (OR 0.95, 95\% CI o.69-I.30, $\left.\mathrm{I}^{2}=0 \%\right)^{8,9,15}$

\section{Transfusion-related outcomes}

The ability of erythropoietin to prevent the need for at least I red blood cell transfusion (i.e., transfusion independence) was evaluated in 7 studies. ${ }^{1,8-12,15}$ Erythropoietin, compared with placebo, significantly reduced the odds of a patient receiving at least I transfusion (OR $0.73,95 \% \mathrm{CI} 0.64-0.84$, $I^{2}=54.7 \%$ ) (Figure 4 ). Significant heterogeneity was evident in the pooled estimate, which could not be explained by variations in drug dosing, transfusion strategy (restrictive v. liberal), patient population or methodologic quality. The baseline transfusion rate did not correlate with individual study effect sizes.

The impact of erythropoietin therapy on the mean number

Table 3: Erythropoietin- and transfusion-related adverse events reported in the 9 studies included in the systematic review

Erythropoietin-related adverse events;

no. (\%) of events

\begin{tabular}{|c|c|c|c|c|c|c|c|}
\hline Study & $\begin{array}{l}\text { Myocardial } \\
\text { infarction }\end{array}$ & Stroke & Hypertension & $\begin{array}{l}\text { Deep venous } \\
\text { thrombosis }\end{array}$ & $\begin{array}{l}\text { Blood-stream } \\
\text { infection or } \\
\text { sepsis }\end{array}$ & $\begin{array}{l}\text { Transfusion } \\
\text { reaction }\end{array}$ & $\begin{array}{c}\text { Pulmonary } \\
\text { edema }\end{array}$ \\
\hline Gabriel et $\mathrm{al}^{10}$ & NR & NR & NR & NR & NR & NR & NR \\
\hline Corwin et $\mathrm{al}^{1}$ & NR & NR & NR & $\begin{array}{l}\text { EPO: } 4(5.0) \\
\text { Control: } 4(5.0)\end{array}$ & NR & NR & NR \\
\hline $\begin{array}{l}\text { Van Iperen } \\
\text { et } \mathrm{al}^{14}\end{array}$ & NR & NR & NR & NR & NR & NR & NR \\
\hline Corwin et $\mathrm{al}^{8}$ & NR & NR & NR & $\begin{array}{l}\text { EPO: } 14(2.1) \\
\text { Control: } 15(2.3)\end{array}$ & $\begin{array}{l}\text { EPO: } 31(4.7) \\
\text { Control: } 30(4.6)\end{array}$ & NR & NR \\
\hline $\begin{array}{l}\text { Georgopoulos } \\
\text { et } \mathrm{al}^{11}\end{array}$ & NR & $\begin{array}{l}\text { EPO: } 4(4.0) \\
\text { Control: } 3(6.2)\end{array}$ & NR & $\begin{array}{l}\text { EPO: } 1(1.0) \\
\text { Control: } 2(4.2)\end{array}$ & NR & NR & NR \\
\hline Corwin et $\mathrm{al}^{9}$ & $\begin{array}{l}\text { EPO: } 15(2.1) \\
\text { Control: } 6(0.8)\end{array}$ & $\begin{array}{l}\text { EPO: } 14(1.9) \\
\text { Control: } 16(2.2)\end{array}$ & NR & $\begin{array}{l}\text { EPO: } 63(8.7) \\
\text { Control: } 42(5.8)\end{array}$ & $\begin{array}{l}\text { EPO: } 47(6.5) \\
\text { Control: } 50(6.9)\end{array}$ & NR & NR \\
\hline
\end{tabular}

Transfusion-related adverse events; no. (\%) of events 
of units of red blood cells transfused per patient was evaluated in 5 of the 9 studies. ${ }^{8,9,11,12,14}$ Erythropoietin use, compared with a placebo or no therapy, was associated with a decrease in the number of units transfused per patient (weighted mean difference $-0.4 \mathrm{I}$ units per patient, $95 \% \mathrm{CI}$ -0.74 to $\left.-0.10, \mathrm{I}^{2}=79.2 \%\right)$. This decrease represents a transfusion savings of less than 0.5 units per patient.

The most recent study reported the widespread adoption of a restrictive transfusion practice (hemoglobin $\leq 80 \mathrm{~g} / \mathrm{L}$ ). ${ }^{9}$ Erythropoietin did not reduce the proportion of patients who required transfusion of at least I unit of red blood cells in the context of a restrictive transfusion strategy.

\section{Publication bias}

We minimized the potential for publication bias by conducting a thorough literature search that included searching grey literature and consulting with content experts. We also generated funnel plots for the outcomes of death and transfusion independence. No obvious patterns in these plots suggested publication bias; however, the inclusion of only 9 studies limits possible inferences. ${ }^{21}$ Variation observed in these plots may have been because of differences in methodologic quality, target populations or treatment regimens.

\section{Interpretation}

We found insufficient evidence to infer that erythropoietin decreases mortality or improves other clinically important outcomes among patients who are critically ill. Overall, the risk of death was decreased by $14 \%$ with erythropoietin use; however, the boundaries of the $95 \%$ confidence interval could not exclude an increase in all-cause mortality as high as $5 \%$. There is no evidence to suggest erythropoietin shortens the length of stay in intensive care units or hospitals or shortens the duration of mechanical ventilation. Erythropoietin reduced the proportion of patients who required red blood cell transfusions; however, this reduction all but disappeared in the latest trial, ${ }^{9}$ which adopted a restrictive transfusion practice. Moreover, about $46 \%$ of patients required a transfusion despite receiving erythropoietin. The number of transfusions saved by use of erythropoietin was less than I unit per patient.

Many of the included trials had limited or discrepant reports of adverse events; thus, it is difficult to ascertain whether erythropoietin use was associated with an increase or a decrease in the occurrence of major adverse events, including myocardial infarction, hypertension, blood-stream infections or transfusion reactions. In the largest and most recent clinical study, ${ }^{9}$ the occurrence of clinically relevant thrombotic vascular events, including deep vein thrombosis, was higher among patients receiving erythropoietin than among those in the control group. Although the pooled OR for deep vein thrombosis did not reach statistical significance, underdetection and underreporting of adverse events probably influenced this analysis.

Erythropoietin did not reduce mortality in the overall intensive care unit population; however, 2 separate studies by Corwin and colleagues reported a significant reduction in mortality among patients with multiple trauma admitted to intensive care units in the United States ${ }^{8,9}$ In this subgroup, the pooled OR for death was 0.42 ( $95 \% \mathrm{CI} 0.29-0.73)$. Al-

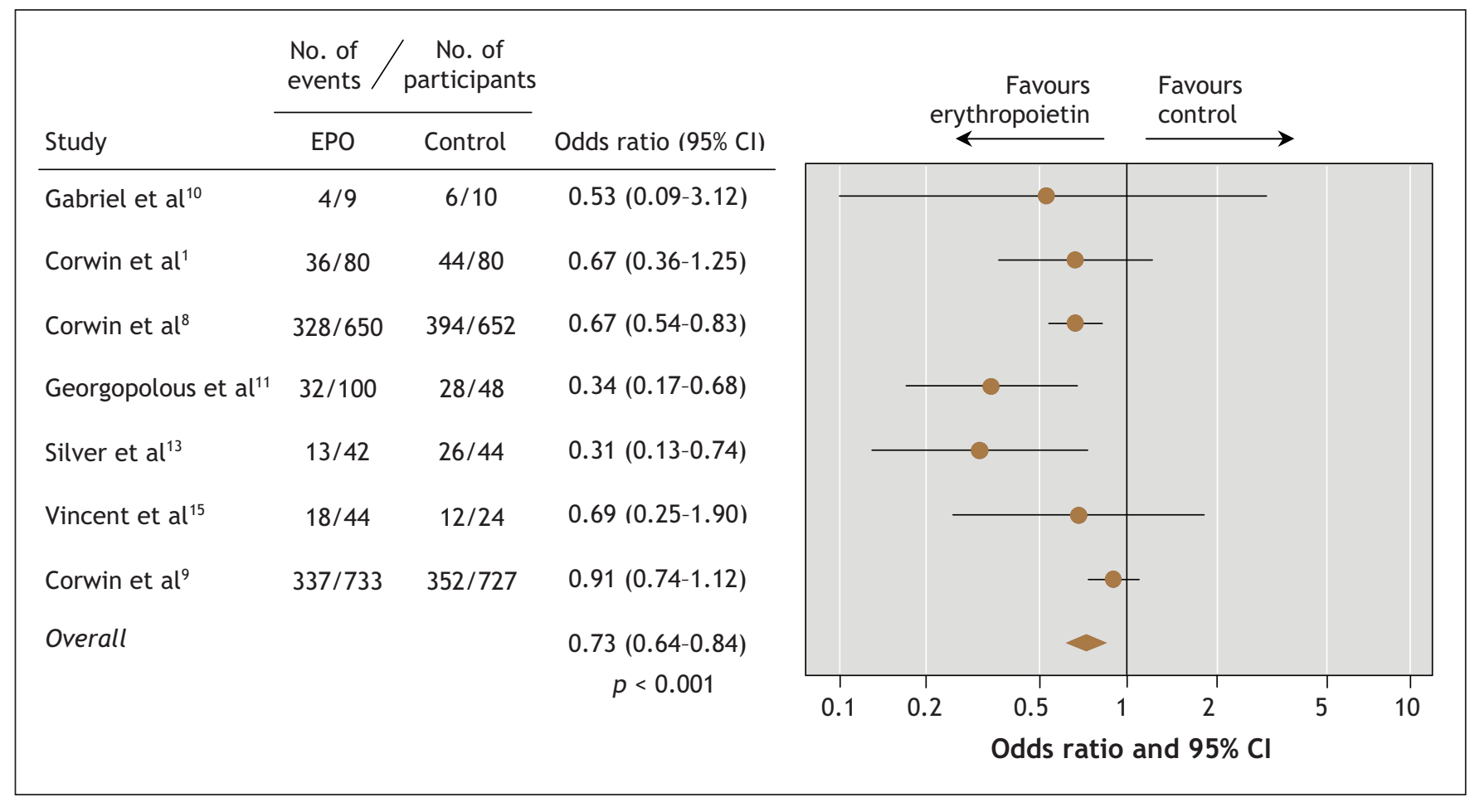

Figure 4: Analysis of transfusion independence among critically ill patients who received erythropoietin or control (placebo or no intervention). $\mathrm{EPO}=$ erythropoietin, $\mathrm{Cl}=$ confidence interval. 
though this analysis is intriguing, it can be interpreted only as hypothesis-generating because pooled analysis of subgroups could amplify systemic bias. Low event rates in the trauma subgroup (29 deaths among 716 with trauma in the erythropoietin group v. 59 deaths among 707 with trauma in the control group) also provide for unstable estimates of the treatment effect. Lastly, as shown in the most recent study, the apparent reduction in mortality in the trauma group occurred in absence of any measurable reduction in transfusions. The current scientific understanding of the transfusion-independent roles of erythropoietin is limited. This finding must be confirmed through future basic science investigations and prospective clinical studies. Cook and Crowther, ${ }^{22}$ commenting on the lastest erythropoietin trial, ${ }^{9}$ urge caution and the need for a large rigorous randomized trial to evaluate whether erythropoietin is beneficial in patients with multiple trauma.

The use of erythropoietin in patients with chronic kidney disease and cancer is known to be associated with specific adverse events, including cardiovascular events and thrombosis. Despite this knowledge, only I study reported adverse events due to myocardial infarction, ${ }^{23}$ and only I study reported events due to hypertension..$^{24}$ Of the 9 included studies, 5 reported events due to deep vein thrombosis. ${ }^{1,8,9,11,14}$ The largest study reported significantly increased rates of deep vein thrombosis and other clinically relevant vascular events associated with erythropoietin use (OR I.55, 95\% CI I.I5-2.I0), despite the exclusion of high-risk patients (history of pulmonary embolus, deep venous thrombosis, ischemic stroke, other arterial or venous thrombotic event or chronic hypercoagulable disorders) with a history of arterial or venous thrombotic events. ${ }^{9}$ We hypothesize that the generalized use of erythropoietin outside the context of a clinical trial in patients who are at high risk of arterial or venous thrombosis will be associated with an even greater risk of adverse thrombotic events and a higher risk-to-benefit ratio. Given the known adverse thrombotic consequences of erythropoietin, future trials must include mechanisms for systematic surveillance to ensure adequate detection of relevant adverse events.

The main limitation of our study is the methodologic limitations of the primary studies. Erythropoietin-dosing regimens and the duration of follow-up varied substantially between the studies. The total dose of erythropoietin administered could not be abstracted for each trial. This limitation is minimized since all dosing regimens were "high" based on the standard indication for this drug. Furthermore, subgroup analysis demonstrated consistent effects among patients receiving more or less than 40000 units of erythropoietin per week. Another limitation of our systematic review is that we did not contact industry representatives to find additional relevant, yet unpublished, studies.

Several measures of study quality have been developed, including the Jadad score and the Schulz criteria. ${ }^{16,17}$ The limitations of these empiric techniques are demonstrated in this review. Although 3 studies received the highest Jadad score attainable, I of the 3 studies had a lost-to-follow-up rate of $27 \%$ and the hemoglobin concentration before transfusion was significantly lower among patients in the control group than among those in the treatment group. ${ }^{12}$ The risk for bias within this trial highlights the need to carefully consider each aspect of the trials included in a systematic review.

Maintaining adequate blinding throughout the duration of a study is essential. Should a study become unblinded, the introduction of systematic error, or bias, threatens its validity. Lower degrees of blinding are associated with greater apparent treatment effects. ${ }^{25}$ Given the availability of hemoglobin measurements in the intensive care unit, blinding procedures could have been compromised in any of the 7 blinded studies included in this review. Formal testing of the blinding strategy was not reported in any of the included studies, and the adequacy of the blinding procedures used is therefore unknown.

In summary, at this time we do not recommend the routine use of erythropoietin-receptor agonists in critically ill patients because of a very small decrease in the use of red blood cell transfusions and insufficient evidence to determine whether treatment results in clinically important benefits. Before widespread use of this product, we recommend further research to better explore potential benefits and harms of erythropoietin-receptor agonists in patients with multiple trauma. We also encourage researchers to conduct and report more detailed evaluations of anticipated and relevant adverse events within clinical trials.

This article has been peer reviewed.

Competing interests: None declared for Ryan Zarychanski, Alexis Turgeon and Lauralyn McIntyre. Dean Fergusson has received unrestricted grants and consultancy monies from Amgen and Ortho Biotech.

Contributors: All of the authors contributed to the study conception and design and to the interpretation of the results. Ryan Zarychanski performed the data analyses and drafted the original manuscript. All of the authors revised the manuscript for important intellectual content and approved the final version submitted for publication.

Acknowledgements: We thank Dr. David Moher for providing instruction and advice about the systematic review process, Mrs. Risa Shorr for her assistance as an information specialist and Dr. Donald S. Houston for his comments and suggestions that have improved the quality of the final manuscript.

Ryan Zarychanski is the recipient of a research fellowship from the Canadian Blood Services and the Ottawa Health Research Institute, Ottawa, Ont. These agencies had no role in the design, conduct or analysis of this study or in the decision to submit the manuscript for publication.

\section{REFERENCES}

I. Corwin HL, Gettinger A, Rodriguez RM, et al. Efficacy of recombinant human erythropoietin in the critically ill patient: a randomized, double-blind, placebo-controlled trial. Crit Care Med I999;27:2346-50.

2. Corwin HL, Gettinger A, Pearl RG, et al. The CRIT Study: anemia and blood transfusion in the critically ill - current clinical practice in the United States. Crit Care Med 2004;32:39-52.

3. Rodriguez RM, Corwin HL, Gettinger A, et al. Nutritional deficiencies and blunted erythropoietin response as causes of the anemia of critical illness. J Crit Care 200I; I6:36-4I.

4. Vincent JL, Baron JF, Reinhart K, et al. Anemia and blood transfusion in critically ill patients. JAMA 2002;288:1499-507.

5. Smoller BR, Kruskall MS. Phlebotomy for diagnostic laboratory tests in adults. Pattern of use and effect on transfusion requirements. N Engl J Med I986;3I4:I233-5.

6. Henry mL, Garner WL, Fabri PJ. Iatrogenic anemia. Am J Surg I986;151:362-3.

7. Corwin HL, Parsonnet KC, Gettinger A. RBC transfusion in the ICU. Is there a reason? Chest 1995;108:767-71.

8. Corwin HL, Gettinger A, Pearl RG, et al. Efficacy of recombinant human erythropoietin in critically ill patients: a randomized controlled trial. JAMA 2002;288: 2827-35. 
9. Corwin HL, Gettinger A, Fabian TC, et al. Efficacy and safety of epoetin alfa in critically ill patients. N Engl J Med 2007;357:965-76.

Io. Gabriel A, Kozek S, Chiari A, et al. High-dose recombinant human erythropoietin stimulates reticulocyte production in patients with multiple organ dysfunction syndrome. J Trauma 1998;44:36I-7.

II. Georgopoulos D, Matamis D, Routsi C, et al. Recombinant human erythropoietin therapy in critically ill patients: a dose-response study [ISRCTN48523317]. Crit Care 2005;9:R508-I5.

I2. Silver M, Corwin MJ, Bazan A, et al. Efficacy of recombinant human erythropoietin in critically ill patients admitted to a long-term acute care facility: a randomized, double-blind, placebo-controlled trial. Crit Care Med 2006;34:2310-6.

I3. Still JM Jr, Belcher K, Law EJ, et al. A double-blinded prospective evaluation of recombinant human erythropoietin in acutely burned patients. J Trauma 1995;38: $233^{-6}$.

I4. Van Iperen CE, Gaillard CA, Kraaijenhagen RJ, et al. Response of erythropoiesis and iron metabolism to recombinant human erythropoietin in intensive care unit patients. Crit Care Med 2000;28:2773-8.

I5. Vincent JL, Spapen HD, Creteur J, et al. Pharmacokinetics and pharmacodynamics of once-weekly subcutaneous epoetin alfa in critically ill patients: results of a randomized, double-blind, placebo-controlled trial. Crit Care Med 2006;34:I66I-7.

I6. Jadad AR, Moore RA, Carroll D, et al. Assessing the quality of reports of randomized clinical trials: Is blinding necessary? Control Clin Trials 1996;I7:I-I2.

I7. Schulz KF, Chalmers I, Hayes RJ, et al. Empirical evidence of bias. Dimensions of methodological quality associated with estimates of treatment effects in controlled trials. JAMA I995;273:408-I2.

I8. Higgins JP, Thompson SG, Deeks JJ, et al. Measuring inconsistency in meta-analyses. $B M J$ 2003;327:557-60.

I9. McGinn T, Wyer PC, Newman TB, et al. Tips for learners of evidence-based medicine: 3 . Measures of observer variability (kappa statistic). CMAJ 2004;171:1369-73.

20. Chakraborty A, Natarajan J, Guilfoyle M, et al. Population pharmacokinetics of erythropoietin in critically ill subjects. J Clin Pharmacol 2005;45:193-202.

2I. Ioannidis JP, Trikalinos TA. The appropriateness of asymmetry tests for publication bias in meta-analyses: a large survey. $C M A J$ 2007;176:I09I-6.

22. Cook D, Crowther M. Targeting anemia with erythropoietin during critical illness. NEngl J Med 2007;357:1037-9.

23. Bohlius J, Wilson J, Seidenfeld J, et al. Erythropoietin or darbepoetin for patients with cancer. [Cochrane review] In: The Cochrane Library; Issue 3, 2006. Oxford: Update Software.

24. Drueke TB, Locatelli F, Clyne N, et al. Normalization of hemoglobin level in patients with chronic kidney disease and anemia. N Engl J Med 2006;355:2071-84.

25. Colditz GA, Miller JN, Mosteller F. How study design affects outcomes in comparisons of therapy. I: Medical. Stat Med I989;8:44I-54.

Correspondence to: Dr. Ryan Zarychanski, Ottawa Health Research Institute, 50I Smyth Rd., Ottawa ON KIH 8L6;

ryan@zarychanski.com

\section{Holiday Review 2007 Call for submissions}

Hilarity and good humour ... help enormously in both the study and the practice of medicine ... [I]t is an unpardonable sin to go about among patients with a long face.

— William Osler

Quirky, contentious or simply fun - we want it all! Yes, it's time to send us your creative missives for CMAJ's Holiday Review 2007. We're looking for humour, spoofs, punchy personal reflections and off-beat scientific explorations.

Please submit online (at http://mc.manuscriptcentral.com/cmaj). Articles should be no longer than 1200 words; photographs and illustrations are welcome. Mention in your cover letter that your submission is intended for this year's Holiday Review.

The deadline for submissions is Oct. 1, 2007.

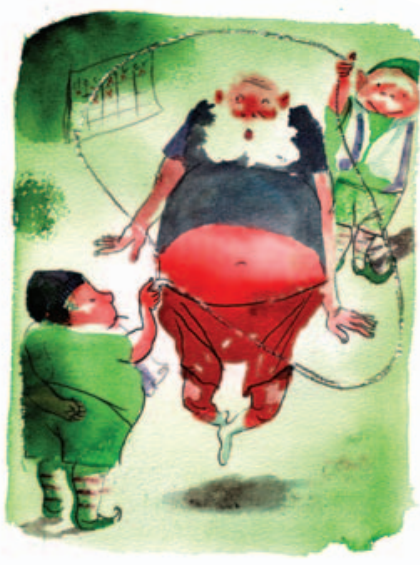

\section{Numéro des Fêtes de 2007 Appel de documents}

L'hilarité et la bonne humeur (...) aident énormément à la fois dans l'étude et dans la pratique de la médecine. (...) Être de mauvaise humeur quand on se présente devant les patients, voilà un péché impardonnable.

$$
\text { - William Osler }
$$

Du bizarre au litigieux, en passant par le simplement divertissant — nous voulons de tout! En effet, le moment est venu de nous faire parvenir vos créations littéraires pour le numéro des Fêtes 2007 du JAMC. Nous recherchons les textes humoristiques, parodies, réflexions personnelles, histoires de la médecine et explorations scientifiques hors de l'ordinaire.

Veuillez nous faire parvenir vos textes par notre système d'envoi de manuscrits en ligne (http://mc.manuscriptcentral .com/cmaj). Les articles ne doivent pas dépasser 1200 mots et les photographies et illustrations sont les bienvenues. Veuillez indiquer dans votre lettre d'accompagnement que vous soumettez votre texte pour le numéro des Fêtes de cette année.

Les textes doivent nous parvenir au plus tard le $\mathbf{1}^{\mathrm{er}}$ octobre 2007. 